\title{
Geodetic Measurement of Longitudinal Displacements of the Railway Bridge
}

\author{
Jaroslav Braun, Martin Štroner \\ Czech Technical University in Prague, Faculty of Civil Engineering, Department of Special \\ Geodesy, Thákurova 7, 16629 Praha 6, Czech Republic, E-mail: jaroslav.braun@fsv.cvut.cz, \\ martin.stroner@fsv.cvut.cz
}

\begin{abstract}
The paper deals with geodetic measurements of mutual longitudinal displacements of construction of the railway bridge and rails on the bridge in Klášterec nad Ohř́. Construction of the bridge is made of steel with a concrete deck, which carries the stone superstructure and rails. The bridge is about 100 meters long and expected deformations are in millimetres. The method of geodetic network with the expected standard deviations of coordinates about $0.2 \mathrm{~mm}$ was chosen. The deformation of the structure was determined to be $4 \mathrm{~mm}$, the deformation of the rails was determined to be $1 \mathrm{~mm}$, both as a result of epoch comparison.
\end{abstract}

Key words: bridge, geodetic network, longitudinal shift, railway, standard deviation, track.

\section{Introduction}

Buildings and constructions are constantly changing by the influence of time, temperature and environment changes, there occur shifts and deformations. For bridge structures, these changes are most obvious and frequently monitored, as they may affect the functionality and safety of the structure. Depending on the type and use of the bridge is chosen measurement procedure, which can continuously monitor deformations of the structure [1] or long-term changes resulting from the change of seasons. For the measurement of displacements and deformations of bridges are used special procedures of engineering surveying, which are applied, as mechanical engineering equipment, high-precision levelling [2], laser scanning [3] or precise geodetic networks. Changes of the structure can be observed by these methods with high precision, with standard deviation often less than $1 \mathrm{~mm}$.

Department of Special Geodesy and Department of Railway Structures, Faculty of Civil Engineering CTU in Prague perform monitoring of the railway bridge near Klášterec nad Ohř́ in north-western Bohemia. On the structure are observed deformations resulting from the season changes and temperature changes. Main attention is focused on the longitudinal changes of the deck and rails, and determination of their dependencies. Due to the expected changes in the position of points on the rails about $1 \mathrm{~mm}$, the accuracy of analysis before measurement sets a requirement to determine the coordinates of points in the longitudinal direction with a standard deviation no larger than $0.2 \mathrm{~mm}$. To achieve this accuracy was designed local geodetic network with 10 free stations and 56 observed points. Since this is an active railroad track with minimal space around tracks, there had to be set up procedures that ensure the required high accuracy, measurement speed, and safety of workers.

\section{Description of Bridge Construction}

Monitored bridge structure is located on the railway line between Klášterec nad Ohri and Pernštejn in north-western Bohemia. The bridge is $8 \mathrm{~m}$ above the river Ohře and is supported at 
3 points (Figure 1). The pillar 1 is attached firmly and on pillars 2 and 3 are movable pot bearings. The supporting steel structure is a lattice beamed with reinforced concrete bridge deck (Figure 3 ). The bridge deck is $85 \mathrm{~m}$ long and $10 \mathrm{~m}$ wide. On the bridge deck is continuous bed of gravel, which stores 2 tracks (straight line).

Gravel is not linked directly to the rails, and therefore the strain of the deck should not influence the strain of the rails. Monitored points were determined on the second track (101-119, 201-219) and on the deck (1002-1013) by the Department of Railway Structures. Points are stabilized by the reflective foils and are glued under the rail head and on deck are glued near the bottom of metal beams of the noise barrier (Figure 2). On the edges of expansion joints between the deck and the pillars are glued points with a center punch $(5001,5002,6001,6002)$ to measure changes in the expansion joint by the mechanical engineering gauge (Figure 2). To geodetic network points were added point 1001 and 1014, stabilized by the reflective foil on the pillars of traction lines.

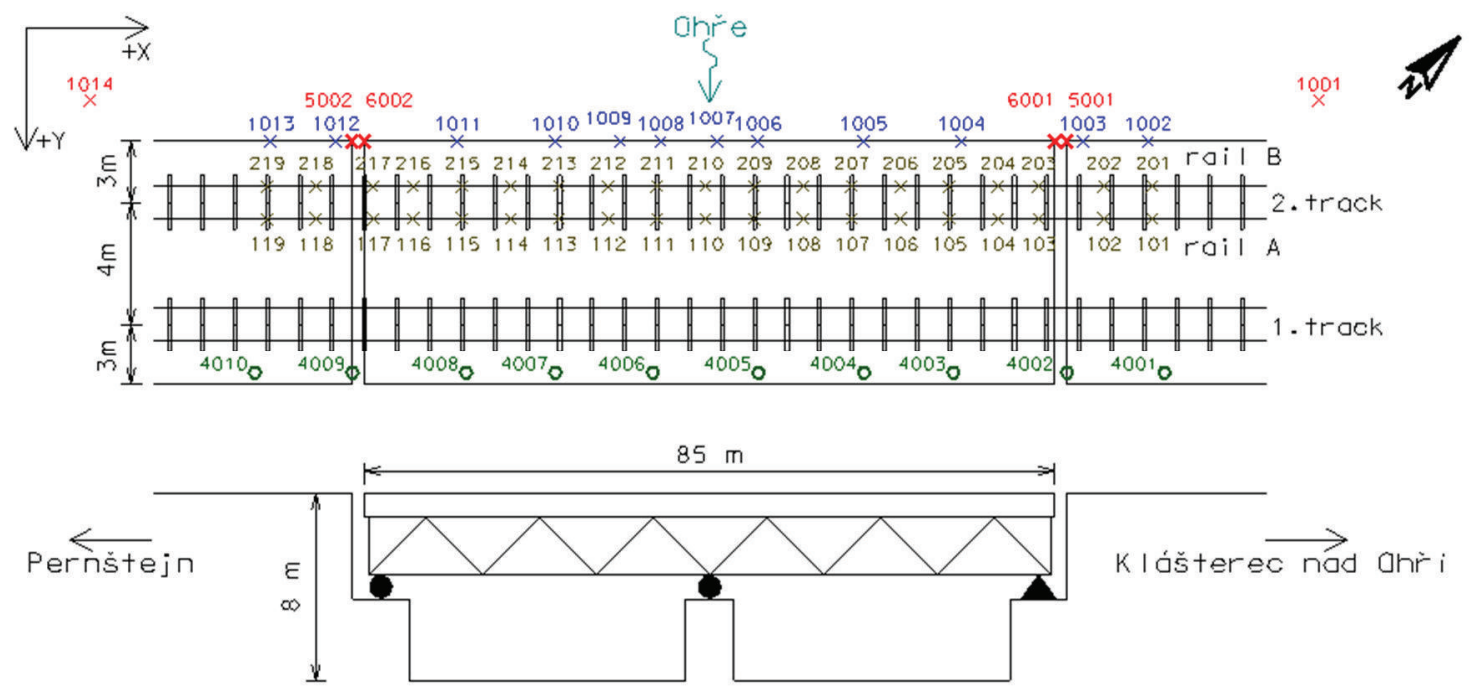

Figure 1: Scheme of bridge construction and points' placement
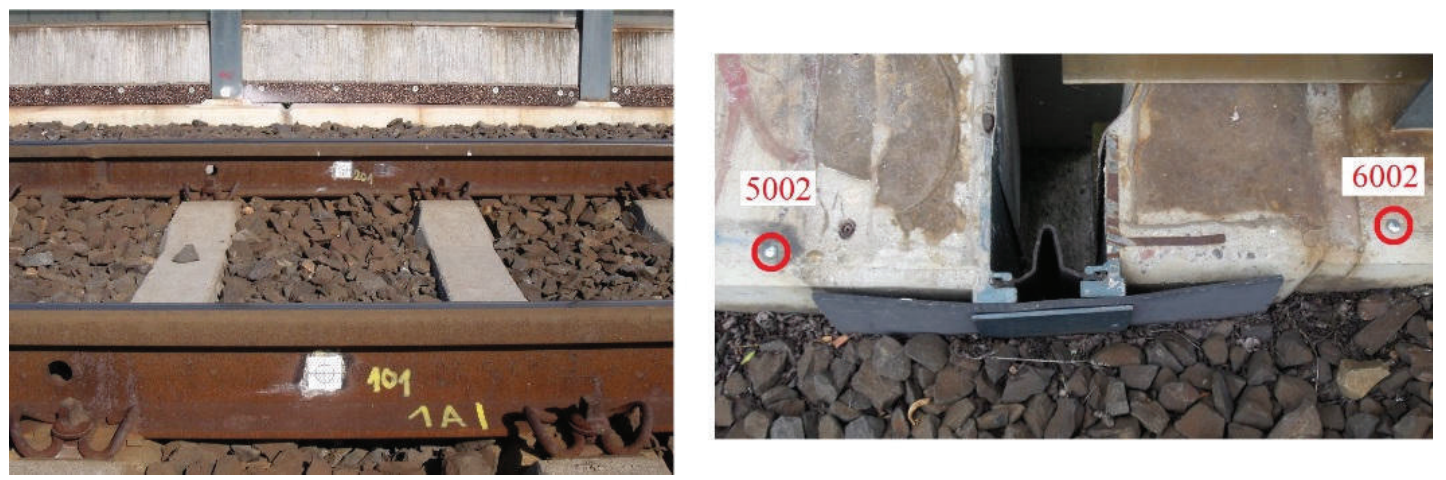

Figure 2: Stabilization of points

\section{A Priori Accuracy Analysis}

To achieve the demanded accuracy, the configuration of geodetic network and measurement accuracy was designed with use of the PrecisPlanner3D software [4]. There was proposed successive measurement from 10 standpoints (4001-4010), which were chosen to be as far as possible from monitored and measured points, thus on the southeast side of the bridge deck. It was designed, that from each standpoint will be measured 4 connecting points $(1001,1014,5001$ a 5002), furthermore at least two points on the deck on each side of the position of the total station 
and at least three sections on rails on each side of the instrument position. Mutual measurement among standpoints is not assumed. This configuration should ensure that each observed point will be measured from at least three standpoints and there will be achieved favourable angles of intersection. When designing the required measurement accuracies it was considered, that targeting on the nearby points will be difficult and it needs an extra care. For direction measuring was chosen standard deviation 1.0 mgon and for slope distances $1.0 \mathrm{~mm}$. The points on the rails were considered only with angular measurements, because the distance measurement may not be possible at all points due to considerably not perpendicular lines of sight against the target reflective foil. Based on these assumptions and the chosen layout of standpoints have been calculated the expected standard deviation of observed coordinates of points which in the longitudinal direction was $0.2 \mathrm{~mm}$.
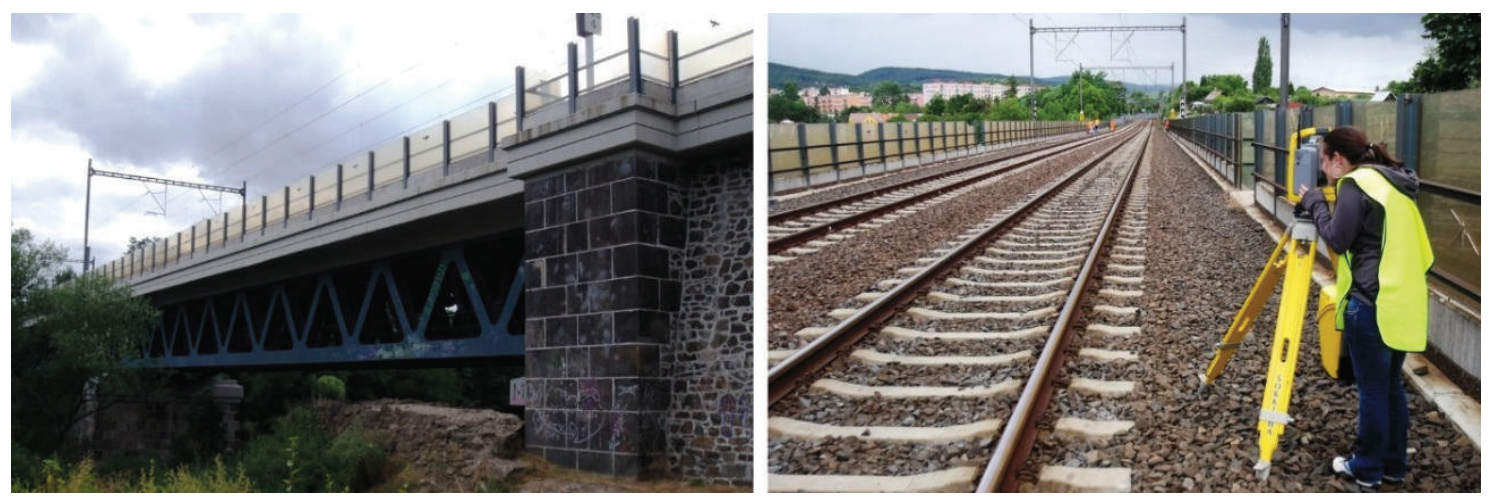

Figure 3: Railway bridge in Klášterec nad Ohř́

\section{Equipment}

For this precise measurement the best available equipment available at the Department of Special Geodesy, Faculty of Civil Engineering CTU in Prague was used, namely total station Trimble S6 HP $\left(\sigma_{\varphi}=\sigma_{\zeta}=0,3 \mathrm{mgon}, \sigma_{\mathrm{D}}=1 \mathrm{~mm}+1 \mathrm{ppm} \cdot \mathrm{D}\right)$. It was also used Leica prism GMP111 for signaling points 5001, 5002, 6001 and 6002 and a digital thermometer and a barometer Greisinger for implementation of physical reduction.

\section{Description of Measurement}

In a priori accuracy analysis was proposed sequential measurement from 10 standpoints and the required measurement accuracy of $1.0 \mathrm{mgon}$ is achieved by the selected total station Trimble S6 by the measurements in one round. Because the measurement is done directly on a bridge when a train passes interruption of the measurement is necessary. When a train passes on track 2, the measurement is interrupted, when a train passes on track 1, it is necessary to leave the bridge. Also there has to be chosen a special procedure for measurement to make it faster and more flexible. At each point is the I. and II. face measured consecutively. The first are measured connecting points $(1001,1014,5001$, and 5002), followed by points on the deck and then points on the rails. In case the measurement is interrupted then the standpoint is measured again, all the connecting points and points on the deck are measured again, and then are measured remaining points on the rails, which were not measured before the interruption. After the completion of all points is required to make a check measurement at least two measured points (usually 1001 and 1014) to verify the stability of standpoint. When measuring distances on foils (points on rails) there was a problem that the angle of incidence was too wide and the instrument was not able to measure in prism mode, so the distances were measured in non-prism mode, but measured distance was not used in the calculation because of the higher standard deviation $\left(\sigma_{\text {Dnp }}=3 \mathrm{~mm}+\right.$ $2 \mathrm{ppm} \cdot \mathrm{D})$. 


\subsection{Epochs of Measurement}

The measurement was carried out so far in three stages under different temperature conditions. Dates of the epochs were chosen with regard to the long-term same temperature conditions due to stabilization of the structure.

1st epoch: $\quad 22.8 .2013(8: 40-14: 00), 14^{\circ} \mathrm{C}-28^{\circ} \mathrm{C}$, cloudy with a gradual clarification, number of measurements: 708 .

2nd epoch: $19.9 .2013(8: 40-12: 45), 9^{\circ} \mathrm{C}-13^{\circ} \mathrm{C}$, cloudy with shift to scattered clouds, number of measurements: 711 .

3rd epoch: $\quad$ 14. 11. $2013(9: 10-13: 30), 1^{\circ} \mathrm{C}-4^{\circ} \mathrm{C}$, cloudy, number of measurements: 780 .

\section{Calculations}

Each of the epochs was calculated separately and adjusted by the least squares method in GNU Gama [5] software with standard deviation $1.0 \mathrm{~mm}$ for slope distances and $1.0 \mathrm{mgon}$ for horizontal directions and zenith angles. Slope distances were used only those, where difference between values measured in the I. and II. face was smaller than $3 \mathrm{~mm}$. Bigger differences could be caused mainly by very slant lines of the sight.

\subsection{Evaluation of Results of the Adjustment}

After alignment is generally appropriate to assess whether the accuracy achieved equivalent accuracy planned before measuring. Testing was performed using the permissible sample standard deviation (according to [6]). Permissible sample standard deviation $s_{M}$ and a posteriori standard deviation $s_{0}$ :

$$
s_{M}=\sigma_{0} \cdot\left(1+\sqrt{\frac{2}{n^{\prime}}}\right) s_{0}=\sqrt{\frac{\boldsymbol{v}^{T} \cdot \boldsymbol{P} \cdot \boldsymbol{v}}{n^{\prime}}}, \boldsymbol{P}=\operatorname{diag}\left(\mathrm{p}_{1}, \mathrm{p}_{2}, \ldots, \mathrm{p}_{\mathrm{i}}, \ldots, \mathrm{p}_{\mathrm{n}}\right), p_{i}=\frac{\sigma_{0}^{2}}{\sigma_{i}^{2}},
$$

where $\sigma_{0}$ is a priori standard deviation used for weight calculation, $n$ ' is number of redundant measurements, $\boldsymbol{v}$ is a vector of corrections after the adjustment, $\boldsymbol{P}$ is (here) diagonal matrix of weights.

\section{2 Results of Epochs Adjustment}

A priori standard deviation was chosen to be 1.0 and there was about 400 redundant measurements in each epoch $\left(s_{M}=1,07\right)$. A posteriori standard deviation was 1.03 in the first epoch, 0.87 in the second and 1.06 in the third one. In all epochs was achieved requested standard deviation of the adjusted coordinates better or equal to $0.2 \mathrm{~mm}$ in longitudinal direction.

\subsection{Check Measurement}

Changes of expansion joints, distances between points 5001-6001 and $5002-6002$ were in each epoch measured by the mechanical engineering gauge. To independently control the results of the geodetic measurement were in the third epoch extra measured points 6001 and 6002 to allow confrontation of geodetic and gauge measurement. Distances calculated from the adjusted coordinates were compared to directly measured distances (by the gauge). Difference was $0.7 \mathrm{~mm}$ for the distance $5001-6001$ and $0.1 \mathrm{~mm}$ for the distance $5002-6002$, both smaller than maximum permissible difference. 


\section{COMPARISON OF EPOCHS}

To compare epochs one to each other must be both in the same coordinate system. Stability of the connecting points was checked by the comparison of the distances determined in epochs.

It was found, that points are not stable and that they change their distances, points 1001 and 1014 even of $5 \mathrm{~mm}$. Therefore were in each epoch given the same coordinates to point 5001 and the $\mathrm{X}+$ coordinate axe is given to be parallel to line $5001-5002$. Coordinates of each point was compared between epochs and plotted (Figure 4), where the first epoch is the reference.

Differences in longitudinal direction between 1. and 2. epoch

(2.-1.; 22.8.2013 $\mathrm{t} \varnothing=21^{\circ} \mathrm{C}, 19.9 .2013 \mathrm{t} \varnothing=11^{\circ} \mathrm{C}$ )

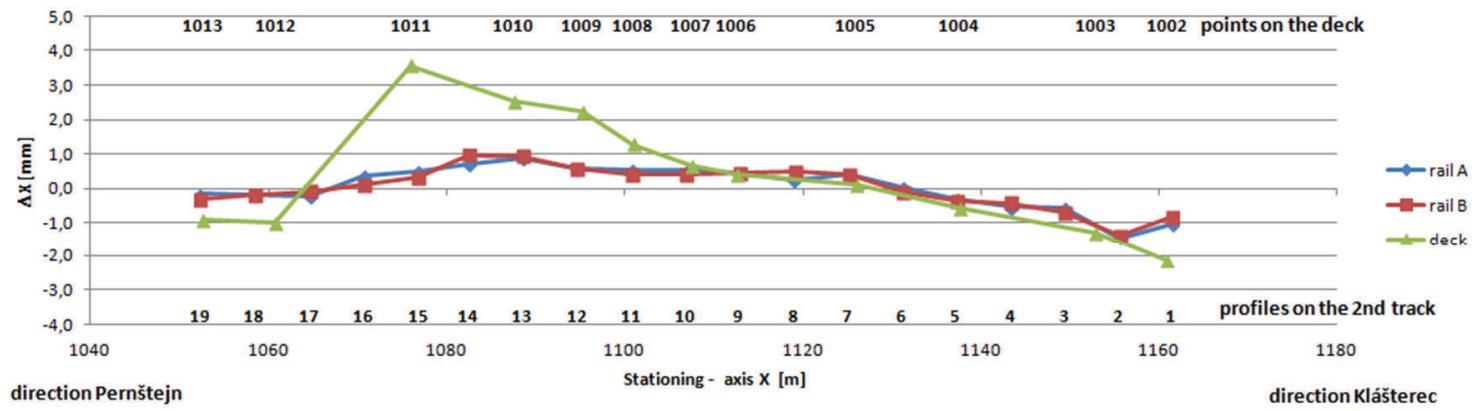

Differences in longitudinal direction between 1. and 3. epoch

(3.-1.; 22.8.2013 $t_{\odot}=21^{\circ} \mathrm{C}, 14.11 .2013 \mathrm{t}_{\odot}=2^{\circ} \mathrm{C}$ )

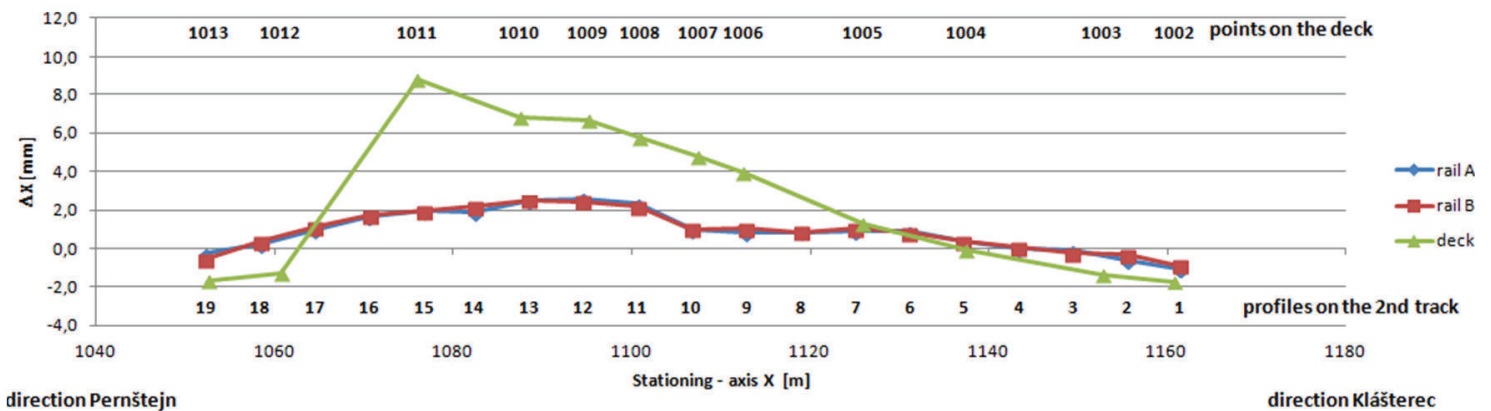

Figure 4: Graphs of longitudinal displacements of points on the rails and deck

The differences in X coordinates represent longitudinal shifts of the points. For all coordinate shifts were calculated maximum permissible differences (on the base of the standard deviations of the adjusted coordinates) according to:

$$
\Delta X_{m e t}=u_{p} \cdot \sqrt{\sigma_{X e t_{-} i}^{2}+\sigma_{X e t_{-} j}^{2}},
$$

where $u_{p}$ is the reliability coefficient (here 2.5 , because the measurement is difficult to check and may be influenced by the systematic errors) and $\sigma_{\text {Xet_i }}$ is standard deviation of the adjusted coordinate. Mean maximum permissible difference is $\Delta X_{\text {met }}=0.8 \mathrm{~mm}$, if this one is exceeded, it can be reasonably expected, that observed point has shifted.

\section{Conclusions}

Longitudinal deformations of the bridge deck and rails were performed on the railway bridge in Klášterec nad Ohří in three epochs. The observing method of local geodetic combined network with ten standpoints was used. Adjusted coordinates were determined with accuracy $0.2 \mathrm{~mm}$ in 
longitudinal direction. From the presented results it implies, that deformation of the bridge deck and the rails are mutually independent. Rails extend of $1 \mathrm{~mm}$ between pillars no. 2 and no. 3 (point $10-17$ ) when the temperature changes of $10^{\circ} \mathrm{C}$, while the bridge deck extends uniformly up to of $4 \mathrm{~mm}$ (points $1004-1011$ ).

\section{Acknowledgements}

The article was written with support from the internal grant of Czech Technical University in Prague No. SGS14/049/OHK1/1T/11 "Optimization of the acquisition and processing of $3 D$ data for the needs of engineering surveying ".

\section{References}

[1] LIPTÁK, I., KOPÁČIK, A., ERDÉLYI, J., KYRINOVIČ, P. (2013). Dynamic Deformation Monitoring of Bridge Structure. Selected Scientific Papers - Journal of Civil Engineering. Vol. 8, Issue 2, pp 13-20, ISSN 1338-7278, DOI: 10.2478/sspjce-2013-0014

[2] BUREŠ, J., KLUSÁČEK, L., NEČAS, R., ŠVÁBENSKÝ, O. (2011). Measuring Technology During Reconstruction of Prestressed Gagarin Bridge. INGEO 2011 Proceedings of the 5th International Conference on Engineering Surveying, ISBN 978-9536082-15-5

[3] KOPÁČIK, A., ERDÉlYI, J., LIPTÁK, I., KYRINOVIČ, P. (2013). Deformation Monitoring of Bridge Structures Using TLS. In 2nd Joint International Symposium on Deformation Monitoring (JISDM). Nottingham: University of Nottingham

[4] ŠTRONER, M. (2010). Vývoj softwaru na plánování přesnosti geodetických měrení PrecisPlanner 3D. Stavební obzor. Vol. 19, No. 3, pp. 92-95. ISSN 1210-4027, (in Czech)

[5] ČEPEK, A. (2013). GNU Gama 1.14 - Adjustment in Geodetic Networks. Edition 1.14 [online]. Available: http://www.gnu.org/software/gama/manual/index.html

[6] ŠTRONER, M., HAMPACHER, M. (2011). Zpracování a analýza měření v inženýrské geodézii (Processing and Analysis of Measurements in Engineering Surveying). $1^{\text {st }}$ edition. Prague: CTU Publishing House. 313 pp., ISBN 978-80-01-04900-6. 